\title{
Burden of Tuberculosis in females in rural area at a tertiary care centre
}

\author{
Sarita Yadav ${ }^{1}$, Shikha Goel ${ }^{2}$, Anand Agrawal ${ }^{3}$ \\ ${ }^{1}$ Assistant Professor, Department of Microbiology, Bhagat Phool Singh, Govt. Medical College for Women, Khanpur Kalan, Sonepat, Haryana, \\ India, ${ }^{2}$ Demonstrator, Department of Microbiology, Bhagat Phool Singh, Govt. Medical College for Women, Khanpur Kalan, Sonepat, Haryana, \\ India, ${ }^{3}$ Associate Professor, Department of Respiratory Medicine, Bhagat Phool Singh, Govt. Medical College for Women, Khanpur Kalan, \\ Sonepat, Haryana, India
}

\section{A B S T R A C T}

Backgroud: Tuberculosis (TB) is the second leading cause of death worldwide amongst communicable diseases. TB kills approximately 1 million women every year and is responsible for more deaths in women in the reproductive age group. Aims and Objectives: The present study was aimed to delineate the burden of disease in women in rural area. Results: High incidence of TB is reported in females of reproductive age group. Conclusion: Routine TB screening should be incorporated into maternal and child health programs in countries where TB is endemic. Revised National Tuberculosis Control Program (RNTCP) should mobilise interventions at rural level to eliminate stigma and ultimately eliminate TB's impact on women.

Access this article online Website:

http://nepjol.info/index.php/AJMS DOI: 10.3126/ajms.v7i1.12604

Key words: Tuberculosis, RNTCP, Women

\section{INTRODUCTION}

Tuberculosis (TB) is the second leading cause of death worldwide amongst communicable diseases. It kills nearly 2 million people each year mostly in the developing countries. ${ }^{1}$ Tuberculosis still exists in India as a significant public health problem. An estimated 1 billion women are affected with TB worldwide. Tuberculosis kills approximately 1 million women every year and is responsible for more deaths in women in the reproductive age group than all causes of maternal mortality combined. ${ }^{2,3}$ There is an estimated 2:1 male to female ratio of cases notified to public health authorities worldwide. ${ }^{4}$ Tuberculosis places pregnant women and their babies at risk. Moreover the confounding factor like associated HIV disease, poverty, nutritional deficiency, social stigma, lack of education and low socio- economic status cause significant delays in the diagnosis and treatment of TB in women. ${ }^{4,5}$

Despite immense impact of TB on women's health, little attention is being paid on measures for control of infection in this particular group especially in rural population. The present study delineates the burden of disease in women especially in reproductive age group, in rural area. This will help health care providers under RNTCP to initiate measures specifically targeting the reproductive age group.

\section{MATERIALS AND METHODS}

The study was conducted at Bhagat Phool Singh, Government Medical College for Women, Khanpur Kalan, Sonepat, which is a 500 bedded tertiary care facility located in rural belt of Haryana, India. The present study is a retrospective record based study carried out from September 2011 to January 2014. All the sputum samples, received in Microbiology Department, were processed by Ziehl Neelsen staining. ${ }^{6}$ All registered cases were stratified into males and females and the results analysed.

\section{RESULTS}

A total of 8934 samples were received in the study period. Table 1 presents the age and sexwise distribution of patients. Out of these, the incidence of positivity was $11.74 \%$ for males and $9.01 \%$ for females. The highest prevalence was seen in the age group 21-30 years (Figure 1). 


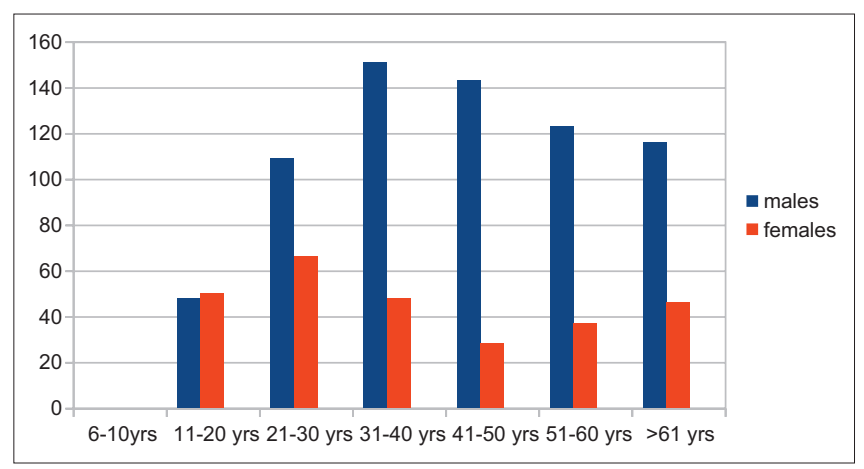

Figure 1: Age \& sexwise distribution of positive cases

\begin{tabular}{lcc}
\multicolumn{3}{l}{ Table 1: Age \& sexwise distribution of cases } \\
\hline Age group (years) & Males & Females \\
\hline $6-10$ & 30 & 20 \\
$11-20$ & 378 & 252 \\
$21-30$ & 676 & 488 \\
$31-40$ & 888 & 527 \\
$41-50$ & 1072 & 564 \\
$51-60$ & 1283 & 588 \\
$>61$ & 1546 & 603 \\
Total & 5873 & 3042 \\
\hline
\end{tabular}

However, as the age advances, the positivity rate showed a decreased trend.

\section{DISCUSSION}

According to World Health Organisation, in 2012, globally more than half of the estimated number of female tuberculosis cases went undetected, compared with less than $40 \%$ in the total population. ${ }^{7}$ Many studies have reported a higher notification rates for males as compared to females. ${ }^{1,2}$ In the present study also, the number of females seeking care is almost half as that of the males. The possible explanation for this might be that, in rural areas, women have reduced access to economic resources, and fewer educational opportunities as compared to men. As a result, many women are unable to locate and reach qualified health services. Studies have also reported that women bear the highest burden of stigmatizing behaviors. In some communities, female TB patients and women who are suspected to have active TB are likely to be forced to get divorced, send back to their parents' homes, and have fewer chances of getting married. ${ }^{8}$

Gender inequality in this domain, has severe consequences in public health in terms of women's poorer access to health care, delay in diagnosis \& treatment of the disease. ${ }^{9}$ In developing countries, TB remains the third leading cause of death among women of reproductive age (15-44) years, disproportionately affecting pregnant women and the poor. ${ }^{4,5,7}$ The analysis of data in the present study reveals that number of females affected are more in age group 21-30 years followed by 11-20 years age group. This is in consistent with findings by Mukherjee et a ${ }^{8}$ and various other authors. ${ }^{10}$ Once infected, women are more susceptible to develop disease than men of the same age. In developing countries, women of the reproductive age group often cook indoors in very confined spaces using biomass fuel such as wood or animal dung, which is again a confounding factor contributing to development of TB. The impact of TB in women is thus severe not only on their families but also on the development of society through loss of workforce, ruined families and orphaned children.

India's Revised National Tuberculosis Control Programme (RNTCP), implemented since 1993, was the second largest DOTS programme in the world by mid-2001, covering more than 400 million people. This programme mainly relies on passive case detection but it is suggested that in rural areas, active case detection should be started to assure gender-equitable access. Routine TB screening should be incorporated into maternal and child health programs in countries where TB is endemic. RNTCP should mobilise interventions at rural level and promote more involvement of lady health workers to improve earlier identification of those who are ill.

Tuberculosis and infectious disease proponents and maternal and child health care workers must work better together on a common agenda to eliminate stigma and ultimately eliminate TB's impact on women.

\section{REFERENCES}

1. Frieden TR, Sterling TR, Munsiff S, Watt CJ and Dye C. Tuberculosis. The Lancet 2003; 362: 887-899.

2. Central TB division. TB India 2007; RNTCP Status Report 2007. Central TB Division, Directorate General of Health services, Ministry of Health and Family Welfare, New Delhi.

3. Thorson A and Diwan VK. Gender inequalities in tuberculosis: Aspects of infection, notification rates, and compliance. Curr Opin Pulm Med 2001; 7: 165-169.

4. Kumaresan JA, Raviglione MC and Murray CJL. Tuberculosis. In: Murray CJL, Lopez AD,eds. The global burden of disease and risk factors in 1990. Switzerland: World Health Organisation Press, 1996.

5. Connolly M and Nunn P. Women and tuberculosis. World health stat q. 1996; 49(2): 115-119.

6. Collee JG, Duguid JP, Fraser AG, Marmion BP and Simmons AC. Laboratory diagnosis of infective syndromes. In: Collee JG, Fraser AG, Marmion BP and Simmons AC, eds. Mackie and McCartney Practical Medical Microbiology. $14^{\text {th }}$ ed. New York: Churchill Livingstone, 1996, pp 53-94.

7. World Health Organisation. Tuberculosis in women, WHO Report 2013. Geneva: WHO,2013.

8. Women and tuberculosis: taking a look at a neglected issue 
[cited 2015 January 18]. Available from: URL: http://www.action. org./advocacy to control tb internationally.html.

9. Mukherjee A, Saha I, Sarkar A and Chowdhury R. Gender differences in notification rates, clinical forms and treatment outcome of tuberculosis patients under the RNTCP. Lung India 2012; 29(2): 120-122.

10. Diwan $\vee$ and Thorson A. Sex,gender and tuberculosis. The Lancet 1999; 353: 1000-1001.

Authors Contribution:

AA- Provided clinical data, SG- Compilation of the data.

Source of Funding: Nil, Conflict of Interest: None declared. 